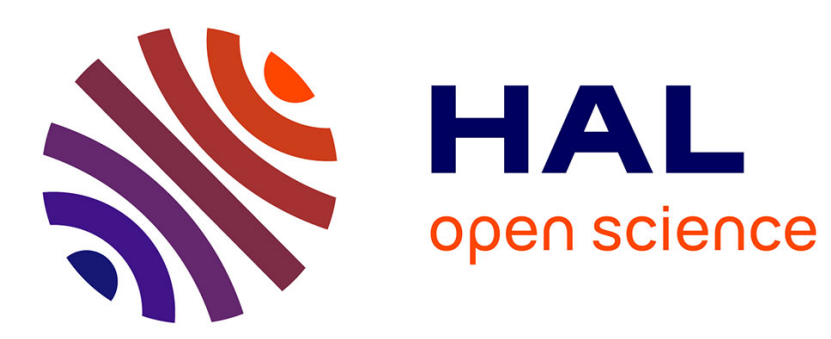

\title{
Modal History versus Counterfactual History: History as Intention
}

\author{
Vasil Penchev
}

\section{To cite this version:}

Vasil Penchev. Modal History versus Counterfactual History: History as Intention. 2021. hal03317883

\section{HAL Id: hal-03317883 \\ https://hal.science/hal-03317883}

Preprint submitted on 8 Aug 2021

HAL is a multi-disciplinary open access archive for the deposit and dissemination of scientific research documents, whether they are published or not. The documents may come from teaching and research institutions in France or abroad, or from public or private research centers.
L'archive ouverte pluridisciplinaire HAL, est destinée au dépôt et à la diffusion de documents scientifiques de niveau recherche, publiés ou non, émanant des établissements d'enseignement et de recherche français ou étrangers, des laboratoires publics ou privés. 


\title{
Modal History versus Counterfactual History: History as Intention
}

\author{
Vasil Penchev, vasildinev@gmail.com \\ Bulgarian Academy of Sciences: Institute of Philosophy and Sociology: \\ dept. of Philosophy of science
}

\begin{abstract}
The distinction of whether real or counterfactual history makes sense only post factum. However, modal history is to be defined only as ones' intention and thus, ex-ante. Modal history is probable history, and its probability is subjective. One needs phenomenological "epoché" in relation to its reality (respectively, counterfactuality). Thus, modal history describes historical "phenomena" in Husserl's sense and would need a specific application of phenomenological reduction, which can be called historical reduction. Modal history doubles history just as the recorded history of historiography does it. That doubling is a necessary condition of historical objectivity including one's subjectivity: whether actors', ex-ante or historians', post factum. The objectivity doubled by ones' subjectivity constitutes a "hermeneutical circle".
\end{abstract}

Keywords: counterfactual history, historiography, hermeneutical circle, historical objectivity, historical phenomenon, historical reduction, historical subjectivity, history as intention, modal history

\section{MODAL HISTORY AND HISTORY AS INTENTION}

Here are a few main obstacles for history to be an objective science:

History is usually classified as a humanitarian science. It can be compared with other humanitarian science such as philosophical metaphysics being unfalsifiable definitively. History is traditionally also unfalsifiable, but in a different sense. Its subject is postulated not to admit "conditional mood" as far as all historical facts are granted to be unique without any alternatives. However, Popper's falsifiability as a condition of any objective science needs for any historical fact to be at least thinkable also as a refutable conjecture.

However, some historians state that conditional mood is "forbidden" in history:

If a fact granted to be historical and thus real is admissible not to have happened, one can suggest an alternative course of history, which also should not happen as far as the alternative version of the historical fact at issue would have many causal consequences further: they would not happen in general, though. Following the same idea, one would be to substitute any real fact by a relevant bifurcation containing at least one alternative different from that which has taken place really. Then, the branch after any bifurcation of those is to be written down right in the "forbidden" conditional mood.

Counterfactual history can be considered as an example of history in a conditional mood. Then one can define "counterfactual history" as an alternative branch of history, unreal and written in the discourse of conditional mood. However, counterfactual history seems to be rather literature than science, even not to speak about an objective science:

Indeed, the only tool relevant to writing counterfactual history is the author's imagination and even, "wild fantasy" without any rational procedure of verification. So, the 
falsifiability, for which counterfactual history was introduced, turns out to be unattainable again in counterfactual history not less than in the standard historiography.

Rather unexpectedly, but quantum mechanics can offer a paradigm for history to be an objective science:

Anyway, one can admit that the failure is due to the paradigm of classical objectivity being irrelevant to historical objectivity. Indeed, classical objectivity suggests a "transparent observer" not influencing definitively on the fact at issue. However, any historian "observes" the corresponding fact only by discourse describing the fact not transparently: any historical fact exists only as recorded being past definitively.

So, the generalized objectivity of quantum mechanics including the "apparatus" (respectively the "observer") can be more relevant to history than the "transparent" paradigm of classical science. For example, those histories being many rather than a single one can occur in different Feynman's pathways:

Meaning the paradigm of quantum mechanics to history, one can suggest many histories not interacting with each other, but ongoing as if simultaneously. One may involve the visualization of the interpretation "by many worlds and histories" in quantum mechanics, in which any world and its history is equally real and an objective probability can be assigned to each of them according to the probability of the corresponding alternative in its beginning. At last, the assigned probability can be interpreted as quantum (i.e. both objective and subjective), and the history of the world, as a Feynman pathway.

One can distinguish real, alternative, and counterfactual history from each other. Meaning the idea of many histories in Feynman's pathways, one can distinguish real, alternative and counterfactual histories as follows:

"Real history" is a single one definitively, and the observer is within it: the historical description is internal, including both observer and discourse within the observed and described.

"Alternative history" is a real history, however, described by an external observer out of it: e.g. the history of China observed from Europe.

"Counterfactual history" is similar to an alternative history, but unlike it not being real: e.g. the history meant by Philip Dick's “The Man in the High Castle”.

The distinction of historical actors versus scientists, historians is obvious. Two fundamentally inverse viewpoints to history exist: that of historical actors involved in history and creating it versus that of scientists, historians only describing it "outside" and observing it by the distance of time. The former viewpoint is ex-ante, and the latter is post factum. Nonetheless, both are partly similar to each other, sharing ones' human subjectivity being inseparable from the historical process itself and by itself. As psychology, history shares troubles about its relation to the modern cognitive episteme directed to the gapped distinction of the philosophical "subject and object" (or the Cartesian "mind and body").

One can infer further the distinction of "subjective history" versus "objective history". Indeed, following the dualistic paradigm of science and cognition, one can distinguish disjunctively "subjective history" from "objective history", namely: 
There always exists some historical process by itself and independent of any human subjectivity.

There exist humans such as historical actors or scientists related directly to the historical process at issue: the former ones can influence it, but the latter ones cannot. So, history as science refers only to those who cannot influence on historical facts just according to the dualistic paradigm.

Once one has involved "subjective history", "modal history" can be situated within it. "Modal history" can be introduced as a kind of subjective history also and not worse even within the framework of Cartesian dualism. Historians study objectively the way for the historical actors' views, opinions, outlooks, conceptions, ideas, judgements, etc. to have been influencing the historical process "by itself" therefore changing it more or less essentially. So, those "mental facts" can be considered in accordance with the modern paradigm of scientific objectivity. An objective modal history of mental historical facts seems to be possible, not less that of the happened historical facts.

Furthermore, one can distinguish the objectivity of history by the historians versus that by the actors' modal history. Thus, the standard paradigm of scientifity applied as to history suggests for scientists, historians to be transparent observers studying only objective facts whether material or mental and not influencing them in any way.

However, the historians choose which facts to be studied as well as the discourse by which to be represented: so, the same history written by different historians especially in different epochs can be essentially and even absolutely different. Thus, the subjectivity of historians can be not less crucial than actors' as to the written history: one can introduce the historians' modalities as another subject of "modal history".

Even more, historians' modality can be equated to actors' modality both being studied by modal history even in a way not to be distinguishable from each other. Nonetheless, those modalities conserve a polar opposition: the former is ex-ante, but the latter is post factum. The one can be transformed into the other only by reversing the direction of time being the "normal" one only for the actors. For example, the conception of "hermeneutical circle" can link them to each other as a shared "hermeneutical modality", to which each of them is only the one "half".

Following the same trace, the hermeneutics of intention would be relevant. One can complement the hermeneutics of fact by the hermeneutics of intention and even consider them as complementary to each other. However, the "hermeneutics of intention" is an unambiguous concept being able to mean as an interpretation of intention by historians, i.e. post factum, as the intention itself as an interpretation of fact, i.e. ex-ante. The latter hermeneutics is related to historians' interpretation of the fact as dual to it and able to represent it ex-ante. The former hermeneutics is also related to the same historians' interpretations as dual but being co-temporal to it, i.e. again ex-ante.

However, the opposite viewpoint of intention as hermeneutics is not less relevant. One can consider intention as hermeneutics in detail. The historical actors are deprived of the opportunity to observe the historical process as a whole, as accomplished, or as historians are able. They are involved immanently in the historical process, but they can influence it 
therefor. A "metaphor of equation" can elucidate the interrelation. "Historical discourse can be equated to historical intention": on virtue of doubling reality whether past (the former) or future (the latter).

Intention is doubling. One can state that historical intention does the same as historical discourse, namely doubling reality though ex-ante or post factum correspondingly. So, one can concentrate on the necessity of any historical fact to be doubled as a definitive condition of it, i.e. being just a historical fact. That doubling is necessary fundamentally: to constitute the fact in relation to the totality or as a "particular totality". Indeed, doubling the fact by its counterpart whether external as its discursive image or internal as intentions to be influenced on the future is its transcendental condition, i.e. to be relatable to the totality.

Transcendentality can be demonstrated by intention as well. Still one metaphor might be coined: the historians are "Brecht historical actors" (and the historical actors themselves ar "Stanislavski ones"), or: "Stanislavski historians going beyond portraying by discourse in order to become actors literally". Then, one can understand intention as a key to transcendentality for all those involved in the historical process as its actors or as if "actors recreating it by Stanislavski's method". The transcendental viewpoint to history or its philosophy identify historical actors and historians as two modifications of the same transcendental essence.

The concept of "transcendental intention" can be a relevant generalization. Intention being a general key to transcendentality making it accessible "inside of the totality" can be conceptualized as "transcendental intention" or the "intention of transcendentality". As if the transcendentality itself is gifted by the human capability to intend. The necessary condition of intention is one's temporality, i.e. being within time. So, the idea of transcendental intention gives the transcendentality though being not less atemporal, i.e. out of time, by the property to be within it in virtue of the totality of the totality.

\section{FOLLOWING HUSSERL'S PHENOMENOLOGY AS A METHODOLOGY OF HISTORY}

Discourse and intention can be as opposed as unified. The scientists historians can be as opposed as unified with the historic actors as to any historic process or facts. The aspect of their unification can be thought of as an underlying structure, the inseparable "discourse \& intention". The temporality of the same structure turns out to be reversible necessarily since it has unified the description "post factum" (for discourse and directed "backwards" in time) with representation "ex-ante" (for intention and directed forwards in time). The state of "discourse \& intention" seems to be a coherent state in the sense of quantum mechanics.

Husserl will be followed explicitly in a few papers $(1927,1911)$ of his.

One can think of a new "epoché" opposed to Husserl's in a sense. Husserl's phenomenology uses the concept of "epoché" unifying reality \& conscious, or the Cartesians "body" \& "mind", or German classical philosophy's "subject" and "object" meaning the concept of phenomenon as what "remains" regardless of which member be chosen (the former or the latter) of any opposition of those. That kind of "epoché" can be called objective and opposed to a conjectural "subjective epoche", which is to be 
introduced. It should mean an epoché in relation to "which subject": for example, whether the historical subjects are historical actors and their intentions or scientists, historians with their corresponding discourses.

Then, the objectivity of history can be defined by a relevant "epoche". If one grants that kind of "subjective epoché" as to history, historical action and historical study would turn out to be indistinguishable from each other. Any historical action can be considered as a corresponding historical discourse or transformable into it, and vice versa as well. The objectivity of history is to be defined as being regardless of "which subject", first of all, which kind: whether historians or actors, but furthermore as regardless of which among any representatives of both groups. In other words, the objective historical cognition is to be independent of its subject whether involved into and within the historical process at issue or not.

Meaning the same viewpoint, the standard historiography turns out to be subjective. Meaning that objectivity of history in relation to "subjective epoché" as in the previous paragraph: the alleged "objectivity of the standard historiography" is to be re-estimated as seeming, ostensible. It privileges the viewpoint of the historians, post factum, but hides or even imposes a "taboo" on how the "historical facts" and "relevant discourse" had been chosen. Both "historical facts" and "relevant discourse" suggest an implicit subject and thus, subjectivity is even "tabooed". Consequently, the objectivity of the standard historiography is alleged, ostensible, and grounded on an arbitrarily subjectivity withal forbidden for criticism, discussion, or even articulation.

Thus, the concept of "epoché" for history seems to be necessary. Meaning that real subjectivity of the standard historiography, the necessity of "subjective epoché" for history can be justified as follows. Objectivity as being independent of any subject means for history to be invariant to the choice of subject, especially whether actors or scientists, but postulating the availability of subject as necessary for historical cognition for its specific engagement with the investigated process. Thus, the classical ideal of scientific objectivity of the "transparent observer" is inapplicable as to historical cognition: its observer influences on the studied necessarily. So, its objectivity is forced to consist in being independent of that influence just by means of that "subjective epoché".

As Husserl's epoché implies his concept of phenomenon, the modified "subjective epoché" would be to imply a kind of "subjective phenomenon", which can be called "historical phenomenon" in the present context. What remains after Husserl's "epoché to reality" is his "phenomenon" being a new interpretation of the namesake concept of transcendentalism in the final analysis though it seems to be quite different at first glance.

So, involving his doctrine of phenomenology called to study right "phenomena", Husserl rejected Cartesian dualism and the cognitive episteme of Modernity at all therefore. Indeed, all phenomenology would be to be located in the gap between "body" and "mind", "subject" and "object", and thus, inaccessible in the framework of dualistic episteme.

Once the concept of "historical epoche" is involved as a corollary and application of Husserl's epoché as to the particular reality of historical facts, this admits an analogical continuation to "historical phenomenon". It can be defined explicitly as what remains from 
a historical fact if its necessary subjectivity identifies the actors' intentions ex-ante and the historians' discourses post factum. "Historical phenomenon" just as Husserl's "phenomenon" rejects the modern dualistic episteme for it would be "zero", i.e. would not make sense within its framework.

Husserl suggested the concepts of eidetic, phenomenological and transcendental reductions. If one considers "epoché" as an counterpart of "phenomenological reduction", the relevant idea can be extended: (1) to mathematics and its foundations ("eidetic reduction"); (2) to philosophy and its foundations ("transcendental reduction"); and (3) even to pure, phenomenological psychology being a possible foundation of the science of psychology (again "phenomenological reduction" but understood already as "psychological reduction" in the present context).

One can introduce "historical reduction" following Husserl's reductions. Thus, after transforming Husserl's "epoché” into "historical epoché" and meaning Husserl's lesson of extending "phenomenological reduction" into "psychological, transcendental and eidetic reduction", one can attempt still one application, now towards history: "historical reduction":

Its result is to be "historical phenomenon" already defined. It can be also explicitly directed to that description of historical fact independent of its author, and especially of author's belonging whether to historical actors or to historians.

One can link the concept of hermeneutic circle to both "historical phenomenon" and "historical reduction". Then, the ontological "hermeneutic circle" involved by Heidegger (1927) and applied to philosophy and methodology of history by Gadamer (1960) can be understand in the present context so:

"Hermeneutic circle" means the unification of "intention" (ex-ante) and "discourse" (post factum), and even, their identification.

Thus, "hermeneutic circle" is both a pathway and working method for historical reduction progressing to historical phenomenon.

Writing means doubling. Derrida $(1967$; 1967a) was the first philosopher who paid attention to the ontological necessity of writing. Writing means what is written to be doubled regardless of being real or not. Thus, writing is a practical and common procedure of Husserl's "epoché" realizing any text (implicitly written) to be understandable philosophically as a phenomenon and the phenomenology itself to be the ontological foundation of human culture being written or documented definitively. Consequently, history as a part of human culture and science need be written therefore doubling the described historical facts in discourse.

Writing implies information and communication, then, time. Any writing including historical represents a series of choices which are conserved and reproducible. Thus, a relevant quality or quantity of information can be assigned to that writing as a text though it refers not only to the explicit text (being "logocentric" by Derrida's term) but rather to all non-happened alternatives of each choice, and therefore constituting its context. Writing implies still one, withal fundamental and transcendental dimension of information: it is 
always a choice for something whether a fact or an idea to be written, i.e. doubled and thus transformed into a phenomenon.

The doubling of historical process by its record brings it out of temporality therefore giving it a meaning independent of time and permanently conserving it (furthermore, as a text being still one and different historical fact coinciding with itself). Thus, writing, regardless of what exactly has been written, is a properly philosophical procedure and method able to generate ontology of anything just out of bringing out of time and describing it "dioptrically" or "relatively": once, within time, and twice, out of time.

Physics, especially quantum mechanics and the theory of quantum information, implicitly means the converse ontology of creation: anything as information and out of time to be investigated as a physical process within time.

The necessity of written history follows doubling. After Gadamer, from Heidegger's hermeneutics as fundamental ontology to the hermeneutic methodology of history, one can think of the necessity of written history as to any historical research and its extremely restricted subject. It needs discourse (whatever it be) as a relevant mirror image of its actors' subjectivity embedded in their intentions. The choice of a certain discourse corresponds to a statement about the influence distribution among all historical actors relevant to what has happened really ("factually"). Then, the practical necessity of written history consists in the importance of actors' intentions as an inseparable part of historical fact, only by which it can be understood in one way or another.

History is to be situated between modal intention and written fact. Meaning that necessity of written history being both ontological and methodological, one can see history as crucified on the opposition of modal intention \& written fact. The actors' modal intention and the historians' written fact can be considered as complementary (in the generalized sense of Niels Bohr) therefore following opposite time directions: ex-ante versus post factum correspondingly. History as an objective science is able to exist only by the tension of modal intention and written fact, but doomed to Sisyphus's work for reconciling them.

\section{INSTEAD OF CONCLUSION: KINDS OF MODAL HISTORY}

Modal history can be considered from the viewpoint of intentions, but not less, from that of facts. Modal history seems to be opposed to historiography studying established and unconditional facts just only after they have happened as such. Thus, modal history is to correspond to actors' intentions describing them as a kind of special mental facts as well as their influence to shape the real historical process. Modal history should consider history ex-ante and by means of actors' intentions realized in the real history only partly, and therefore, the measure of that "partly" can be accepted to correspond to the quality of modality as to modal history. Modal history can be considered as the history of those intentions influenced the real course of history more or less.

Modal history can study the facts of intentions as they have been written in advance as programs, plans, ideas of change, manifestos or as memoirs of actors, serving to concentrate a fan of individual intentions into a single direction therefore able to influence 
history by their unification. Modal history can study the relation of those facts of intentions to real historical facts. Furthermore, modal history can investigate the doubling of facts as both modal and real to be a necessary condition for history to happen.

At last, modal history can be seen as shaped by the tension between a fact and its intention. Modal history can be understood as the history itself if the latter is situated in the tension of intention and fact: "crucified" between the normal course of time, ex-ante, and the reverse time of interpretation, post factum. Modal history would reconcile them and their complementarity in hermeneutical circles, whether in philosophical and historical hermeneutics or by the hermeneutical historical methodology suggested by Gadamer. Furthermore, modal history can research the correspondence or transition of historical intentions into historical discourses sharing similar modality.

Modal history can be compared with historiography. Modal history offers still one viewpoint to history and different from that of the standard historiography: a binocular viewpoint to it. Thus, modal history is crucially necessary for establishing the objectivity of history because the objectivity of history cannot be that of classical science and its "transparent observer". Its creators are involved in it, and even its historians write it in addition though post factum, therefore creating it again, but invisibly and restricting themselves to the "facts".

A few ideas of modal history can be concluded. Modal history can be understood and accordingly defined in different ways even partly incommensurable to each other: (1) modal history of intentions relevant to history; (2) modal history of historical discourses; (3) modal history of both doubling and objectivity as to historical facts; (4) modal history as the hermeneutics of historical facts; (5) modal history of historical modalities.

\section{References:}

Derrida, Jacques (1967) La Voix et le Phénomène: introduction au problème du signe dans la phénoménologie de Husserl, Paris, Presses universitaires de France.

Derrida, Jacques (1967) L'écriture et la difference, Paris, Éditions du Seui

Gadamer, Hans-Georg (1960) Wahrheit und Methode: Grundzüge einer philosophischen Hermeneutik, Tübingen: J.C.B. Mohr.

Heidegger, Martin (1927) Sein und Zeit, Halle, Max Niemeyer.

Husserl, Edmund (1911) Husserl, E. 1911 "Philosophie als strenge Wissenschaft," Logos: Internationale Zeitschrift für die Philosophie der Kultur 3: 289-341.

Husserl, Edmund (1927) “'Phenomenology', Edmund Husserl's Article for the Encyclopaedia Britannica (1927)," (revised translation by R. E. Palmer), in Husserl: Shorter Works (ed. P. McCormick and F. Elliston), Notre Dame: University of Notre Dame Press, 1981, pp. 21-35. 